J. Dairy Sci. 98:718-718

http://dx.doi.org/10.3168/jds.2015-98-1-0718

(C) American Dairy Science Association ${ }^{\circledR}, 2015$.

\title{
Corrigendum to "Evaluation of PCR electrospray-ionization mass spectrometry for rapid molecular diagnosis of bovine mastitis" (J. Dairy Sci. 96:3611-3620)
}

Vincent Perreten, Andrea Endimiani, Andreas Thomann, Juliette R. K. Wipf, Alexandra Rossano, Michèle Bodmer, Andreas Raemy, Kristin A. Sannes-Lowery, David J. Ecker, Rangarajan Sampath, and Robert A. Bonomo

Cicely Washington (Abbott Molecular-Athogen, Carlsbad, CA) was erroneously omitted as a co-author of this article. All authors agree to her addition as an author.

The authors regret the error.

\section{REFERENCE}

Perreten, V., A. Endimiani, A. Thomann, J. R. K. Wipf, A. Rossano, M. Bodmer, A. Raemy, K. A. Sannes-Lowery, D. J. Ecker, R. Sampath, and R. A. Bonomo. 2013. Evaluation of PCR electrosprayionization mass spectrometry for rapid molecular diagnosis of bovine mastitis. J. Dairy Sci. 96(6):3611-3620. 